\title{
The structure of betaxolol from single crystal X-ray diffraction and natural bond orbital analysis
}

\author{
João Canotilho $^{\text {b,* }}$, Ricardo A.E. Castro ${ }^{b}$, Mário T.S. Rosado ${ }^{a}$, M. Ramos Silva ${ }^{c}$, A. Matos Beja ${ }^{c}$, J.A. Paixão ${ }^{c}$, \\ J. Simões Redinha ${ }^{a}$ \\ a Department of Chemistry, University of Coimbra, Rua Larga 3004-535, Portugal \\ ${ }^{\mathrm{b}}$ Center for Pharmaceutical Studies, Faculty of Pharmacy, University of Coimbra, Rua do Norte, 3000-295 Coimbra, Portugal

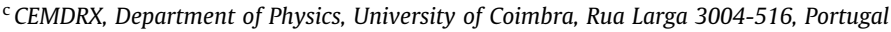

\section{A R T I C L E I N F O}

\section{Article history:}

Received 28 February 2008

Received in revised form 11 April 2008

Accepted 14 April 2008

Available online $\mathrm{xxxx}$

\section{Keywords:}

Betaxolol

Molecular structure

X-ray diffraction

Density functional theory

NBO analysis

Molecular flexibility conformers

\begin{abstract}
A B S T R A C T
The structure of betaxolol obtained from ethanol:water solution was studied by X-ray diffraction. The geometrical parameters needed to define the structure are tabulated. The X-ray data show the existence of two conformers in the unit cell differing only in the conformation of the cyclopropylmethoxy fragment. Differences in the bond lengths angles and dihedral between both conformations are observed. The cyclopropyl groups lie in approximately perpendicular planes.

The two molecular geometries identified by single crystal X-ray diffraction were optimized at the B3LYP/ $6-31 G(d, p)$ level of theory. Both isolated molecules are retained as distinct conformers upon geometry optimization, despite some dihedral relaxation.

The electronic structure of the most important molecular fragments was described in terms of Natural Bond Orbitals. The energetic and spatial features of the occupied and vacant orbitals were studied.

The different structures observed in the solid state were explained by the specific interactions involving the oxygen lone pairs in cyclopropylmethoxy. It was observed some orbital and geometry distortion in cyclopropyl caused by the crystal packing.
\end{abstract}

(c) 2008 Elsevier B.V. All rights reserved.

\section{Introduction}

The knowledge of the structure of a compound in multiple phases used as a medicine is a prerequisite to interpret its chemical and biological activity and to explore further applications [1]. Nowadays, it is common knowledge that minute structural details play an important role in the biological activity or in the properties required by formulation and the chemical and thermal stability of the drug. Hence the interest dedicated to the solid state research by the pharmaceutical industry.

This paper deals with the structure of the betaxolol, 1-[4[2-(cyclopropylmethoxy)ethyl]phenoxy]-3-(1-methylethylamino) propan-2-ol, a common drug used for hypertension and glaucoma treatment. It belongs to the beta blocker class drugs, with which it shares part of its molecular structure. It is specifically a $\beta_{1}$ selective agent [2].

The crystalline structure of betaxolol is characterized experimentally in this work by means of single crystal X-ray diffraction. The electronic structure of the single crystal molecular conformation was studied by Density Functional Theory, using the B3LYP

\footnotetext{
* Corresponding author. Tel.: +351 239859950; fax: +351 239827126

E-mail address: jcano@ci.uc.pt (J. Canotilho).
}

functional with the 6-31(d,p) basis set. This included Natural Bond Orbital (NBO) analysis of the most important orbital interactions, in order to clarify general structural features of $\beta$-blockers and others specific of betaxolol.

\section{Experimental}

\subsection{Preparation and characterization of the crystals}

$(R, S)$-betaxolol (BT) was prepared from its hydrochloride salt kindly provided by Capsifar Ltd. The compound was certified as $99.68 \%$. A purity test by HPLC analysis did not show any extraneous peak in the chromatogram.

The compound was obtained by solvent extraction from an alkaline aqueous solution of betaxolol hydrochloride (BTH) with methylene chloride. The organic phase was dried at $25^{\circ} \mathrm{C}$ in a rotary vacuum evaporator. Crystalline betaxolol was then recrystallized from methanol:water $(20: 80, \mathrm{v} / \mathrm{v})$. Bidistilled water and spectroscopic grade methanol (99.9\% GC) were used. The crystallization was performed by slow evaporation of the solvent.

The microscopic examination of the solid under polarized light shows the presence of birefringent acicular crystals (Fig. 1). The solid was also characterized by Differential Scanning Calorimetry 


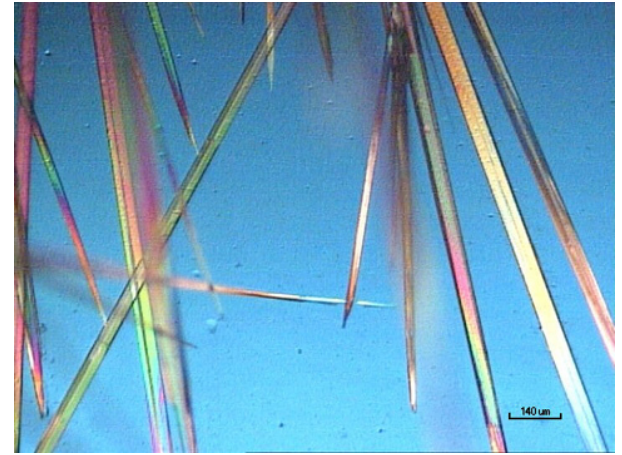

Fig. 1. Photomicrography of $(R, S)$-betaxolol crystals observed under polarized light $50 \times$.

(DSC) with a Pyris 1 Perkin Elmer, following routine calibration procedure. No additional peaks were observed on heating from $25{ }^{\circ} \mathrm{C}$ to fusion (Fig. 2). This phase transition takes place at $T_{\text {on- }}$ set $=(67.49 \pm 0.26){ }^{\circ} \mathrm{C}(n=5)$ and is followed by an enthalpy variation, $\Delta H_{\text {fus }}=(45.9 \pm 0.2) \mathrm{kJ} \mathrm{mol}^{-1}(n=7)$.

\subsection{X-ray data collection and structure determination}

X-ray diffraction measurements were carried out by Mo Ka radiation on a CAD-4 diffractometer equipped with a conventional detector. Data reduction was performed with HELENA [3]. Lorenz and polarization corrections were applied. The structure was solved with direct methods using SHELXS-97 [4], and refined on $F^{2}$ 's by full-matrix least-squares with SHELXL-97 [4]. The anisotropic displacement parameters for non-hydrogen atoms were applied with exception of those that are disordered over two positions. Hydrogen atoms were placed at calculated positions and refined with isotropic parameters as riding atoms.

\section{Results and discussion}

\subsection{Discussion of the X-ray data}

The X-ray diffraction crystal data and details concerning data collection and structure refinement are given in Table 1. The ORTEPII [5] diagram for $(R, S)$-betaxolol using probability ellipsoids are shown in Fig. 3. Atomic coordinates have been deposited at the Cambridge Crystallographic Data Centre and allocated under deposition number CCDC 648386.

The $(R, S)$-betaxolol crystallizes in a centrosymmetric space group P $\overline{1}$. The molecule consists of a central planar phenoxy group, a methylethylamino head and a cyclopropylmethoxy tail (Fig. 3). $\mathrm{C} 13$ also shares the least-squares phenoxy plane with a deviation

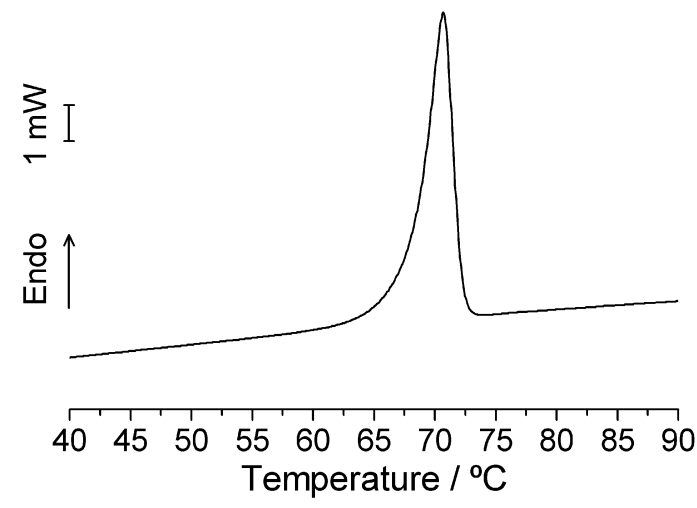

Fig. 2. DSC fusion curve of $\mathrm{BT}$ run at $10{ }^{\circ} \mathrm{C} \mathrm{min}^{-1}$ scanning rate
Table 1

Crystal data and structure refinement parameters for $(R, S)$-betaxolol

\begin{tabular}{ll}
\hline Empirical formula & $\mathrm{C}_{18} \mathrm{H}_{29} \mathrm{NO}_{3}$ \\
\hline Formula weight & 307.42 \\
Temperature $(\mathrm{K})$ & $293(2)$ \\
Wavelength $(\AA)$ & 0.71073 \\
Crystal system & Triclinic \\
Space group & $P \overline{1}$ \\
$a(\AA)$ & $4.9799(11)$ \\
$b(\AA)$ & $10.010(2)$ \\
$c(\AA)$ & $19.123(3)$ \\
$\alpha\left(^{\circ}\right)$ & $103.022(17)$ \\
$\beta\left(^{\circ}\right)$ & $91.29(3)$ \\
$\gamma\left({ }^{\circ}\right)$ & $102.079(16)$ \\
Volume $\left(\AA^{3}\right)$ & $905.8(3)$ \\
$Z$ & 2 \\
Calculated density $/ g$ cm & \\
Absorption coefficient $\left(\mathrm{mm}^{-1}\right)$ & $1.1272(4)$ \\
$F(000)$ & 0.076 \\
Crystal size/mm & 336 \\
$\theta$ Range for data collection $\left(^{\circ}\right)$ & $0.43 \times 0.16 \times 0.12$ \\
Index ranges & $3.29-22.46$ \\
Reflections collected/unique & $-5<h<5,-10<k<10,-20<l<20$ \\
Completeness to $\theta_{\text {max }}(\%)$ & $3925 / 2348[R($ int $)=0.0475]$ \\
Refinement method & 99.7 \\
Data/restraints/parameters & Full-matrix least-squares on $F^{2}$ \\
Goodness-of-fit on $F^{2}$ & $2348 / 0 / 235$ \\
Final $R$ indices $[I>2 \sigma(I)]$ & 1.023 \\
$R$ indices (all data) & $R 1=0.0540 w R 2=0.1455$ \\
Largest diff. peak and hole/e $\AA^{-3}$ & $R 1=0.1119 w R 2=0.1709$ \\
\hline
\end{tabular}

of $-0.007(4) \AA$. In this molecule N1-C3-C2-C1 also shares a plane that makes an angle of $68.0(2)^{\circ}$ with the phenoxy plane. When viewed along the $\mathrm{C} 2-\mathrm{C} 3$ bond, shows a staggered conformation with $\mathrm{C} 1$ trans relative to $\mathrm{N} 1$ and $\mathrm{O} 2$ gauche to $\mathrm{N} 1$, the $\mathrm{O} 2-\mathrm{C} 2-$ C3-N1 torsion angle is $-62.1(4)^{\circ}$.

The cyclopropylmethoxy group has two alternative configurations, differing one from another just from $\mathrm{O} 3$ onwards. The structures $\mathrm{A}$ and $\mathrm{B}$ are detailed in Fig. 4, and can be characterized by geometrical parameters presented in Table 3.

The A and B alternate structures can interconvert by two distinct paths: by rotation of the $\mathrm{O} 3-\mathrm{C} 15$ and $\mathrm{C} 15-\mathrm{C} 16$ bonds or by inversion centered in C16.

The relative occupation is $59 \%$ for $\mathrm{A}$ and $41 \%$ for $\mathrm{B}$. The uncertainty of the cyclopropyl atoms is higher than in the remaining structure. The two planes defined by each of the alternate cyclopropyl positions form an $82^{\circ}$ angle.

The mean value found by experimental techniques for $\mathrm{C}-\mathrm{C}$ length in cyclopropane and derivatives is $1.509 \AA$ with the standard deviations of $0.002 \AA$ [6]. As shown in Table 3, both cyclopropyl groups of betaxolol present significant deviations from this values and deviation between themselves.

The individual molecules are assembled in the crystal in such a fashion that the mutually inverted neighbors face each other head to head and tail to tail. This allows the formation of $\mathrm{H}$-bonds between the hydroxy and amino groups (Fig. 5 and Table 2). Attending to the geometrical parameters the hydrogen bond, when $\mathrm{O} 2-$ $\mathrm{H} 2$ acts as a donor is much stronger then when it acts as acceptor. The $\pi$ electron cloud of the aromatic phenyl ring also acts as an acceptor in this structure joining the molecules along the $a$-axis. The donor (C1)-ring centroid distance is $4.044 \AA$, with a bond angle of $149.4^{\circ}$ and with the shared hydrogen deviating $16.8^{\circ}$ from the ring plane normal. A weak intramolecular bond could also be formed with a hydrogen being shared between $\mathrm{C} 3$ and 01 based only in the relatively large $\mathrm{H}^{\prime}$... 01 distance $(2.57 \AA)$, as the $\mathrm{C} 3$ $\mathrm{H}^{\prime}{ }^{\prime} . . \mathrm{O} 1$ angle is not favorable $\left(101^{\circ}\right)$. However, as can been seen in NBO analysis, no evidence of this interaction was found.

The intermolecular $\mathrm{H}$-bonds join the molecules in ribbons along the $a$-axis as seen in Fig. 5. Each $\mathrm{O} 2-\mathrm{H} 2 \ldots \mathrm{N} 1^{\mathrm{i}}(\mathrm{i})$ and $\mathrm{N} 1-\mathrm{H} 1 \ldots \mathrm{O} 2^{\mathrm{ii}}$ (ii) delineate 10 -membered rings. 


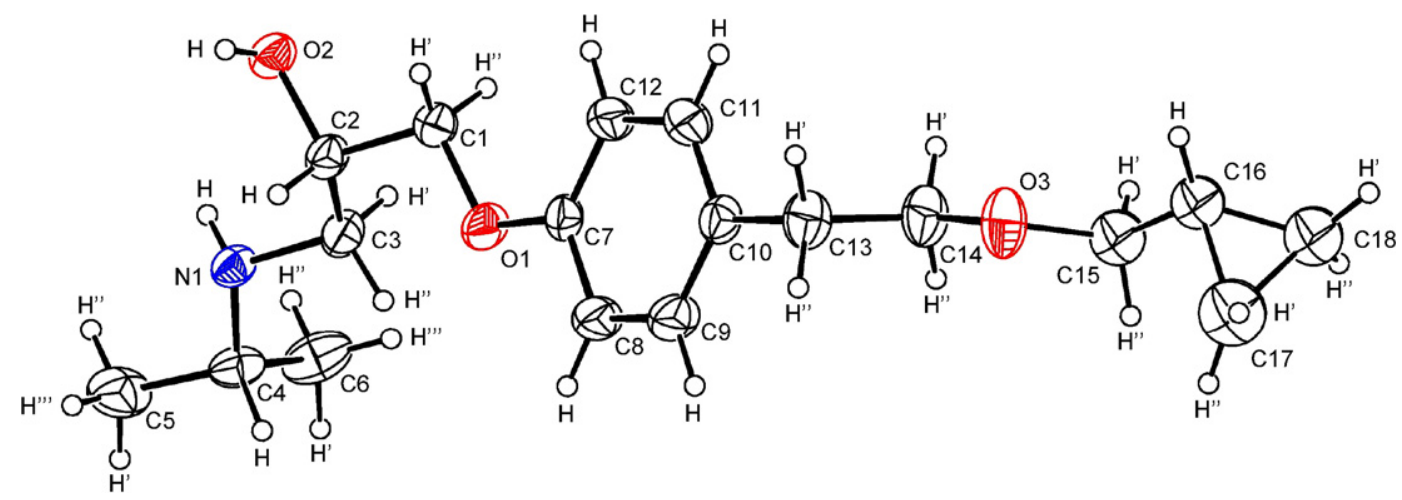

Fig. 3. ORTEPII diagram for $(R, S)$-betaxolol using $50 \%$ probability ellipsoids.

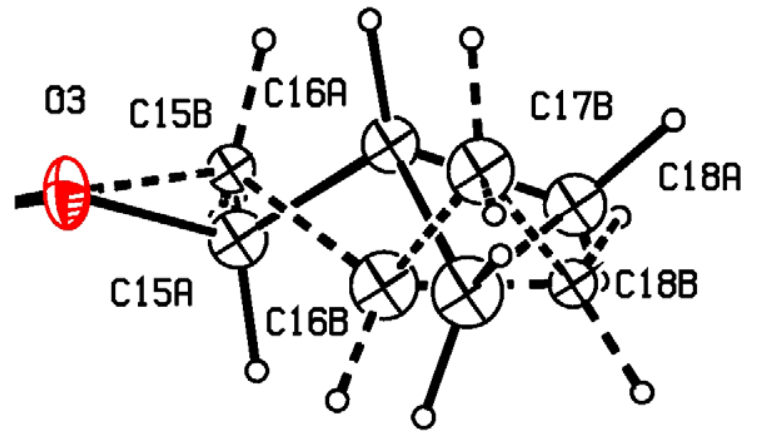

Fig. 4. Relative position of the cyclopropylmethoxy group of A (full) and B (dashed) betaxolol structures using $10 \%$ probability ellipsoids.

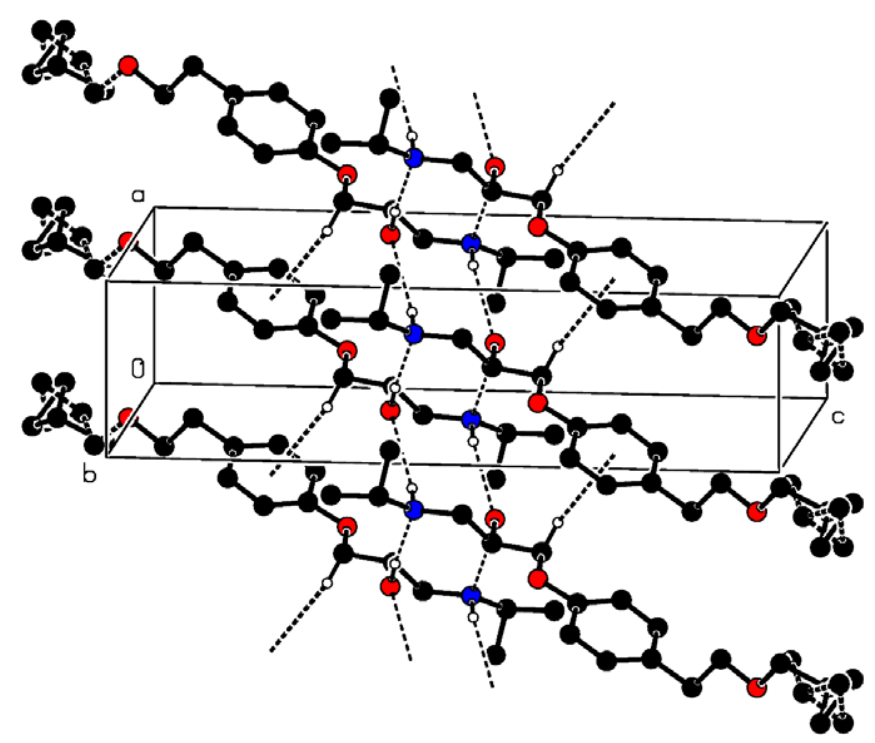

Fig. 5. Packing diagram of $(R, S)$-betaxolol. Intermolecular hydrogen bonds are shown as dashed lines.

\subsection{Geometry optimization of the solid state molecule}

In order to appraise the geometrical constraints of each of the forms A and B in the crystalline structure due to intermolecular forces, their isolated molecules were submitted to geometrical optimization at the B3LYP/6-31G(d,p) [7,8] level of theory, using the GAMESS computational chemistry package [9]. The data obtained for the geometrical parameters of the cyclopropylmethoxy fragment are included in Table 3.
Table 2

H-bond geometry of $(R, S)$-betaxolol

\begin{tabular}{lllll}
\hline & D...A $(\AA)$ & H...A $(\AA)$ & Bond angle $\left({ }^{\circ}\right)$ & Symmetry \\
\hline O2-H2 .N1 & $2.862(4)$ & $2.04(5)$ & $174(4)$ & $1-x, 2-y, 1-z$ \\
$\mathrm{~N} 1-\mathrm{H} 1 \ldots \mathrm{O} 2$ & $3.380(4)$ & $2.56(4)$ & $161(3)$ & $-x, 2-y, 1-z$ \\
\hline
\end{tabular}

Free from intermolecular forces, the molecules relax to the nearest local minima in the potential energy surface. The $\mathrm{C}-\mathrm{C}$ bond angles and distances of cyclopropyl become very similar to those of cyclopropane, but in its vicinity, there are rotations around the C15-C16 and $\mathrm{O} 3-\mathrm{C} 15$ bonds of about $10-30^{\circ}$ (see Table 3 ). On the remainder of the molecular backbone, some other torsional relaxation is also observed for both molecular forms: the C7-01$\mathrm{C} 1-\mathrm{C} 2$ dihedral changes from $160.8^{\circ}$ to $176.3^{\circ}$. To emphasize this, a view of the molecules along the phenyl $(\varphi)$ plane is shown in Fig. 6.

\subsection{NBO analysis}

Despite the accuracy of X-ray diffraction in the determination of the molecular geometry of crystals, it has a few limitations: it should be complemented with other methods when the position of hydrogen atoms is critical. Also, in order to obtain a more complete picture of the electronic structure of the molecules in the betaxolol crystal, the main natural orbital interactions were analyzed with the NBO 5.0 program [10] both for the single point structure and its optimized counterpart.

The lowering of orbital energy due to the interaction between doubly occupied orbitals and unoccupied ones is a very convenient

Table 3

Geometrical parameters of the cyclopropylmethoxy fragment of betaxolol

\begin{tabular}{llllll}
\hline Parameter & \multicolumn{2}{l}{ Crystal structure } & & \multicolumn{2}{l}{ Optimized structure } \\
\cline { 2 - 3 } & $\mathrm{A}$ & $\mathrm{B}$ & & $\mathrm{A}$ & $\mathrm{B}$ \\
\hline Dihedral angles $\left(^{\circ}\right)$ & & & & \\
C1403-C15-C16 & $160.0(7)$ & $-140.2(9)$ & & 178.8 & -172.0 \\
O3-C15-C16-C17 & $96.8(9)$ & $-94(1)$ & & 86.5 & -79.3 \\
O3-C15-C16-C18 & $163.9(8)$ & $-171(1)$ & & 156.8 & -149.8 \\
Bond angles $\left(^{\circ}\right)$ & & & & \\
C16-C17-C18 & $55.2(7)$ & $55.1(9)$ & & 60.1 & 60.1 \\
C17-C18-C16 & $61.9(7)$ & $58.9(1)$ & & 59.9 & 59.9 \\
C17-C16-C18 & $62.9(6)$ & $67(1)$ & & 60.0 & 60.0 \\
Bond length $(\AA)$ & & & & \\
O3-C15 & $1.46(1)$ & $1.41(1)$ & & 1.418 & 1.419 \\
C15-C16 & $1.52(1)$ & $1.66(2)$ & & 1.506 & 1.506 \\
C16-C17 & $1.54(2)$ & $1.44(3)$ & & 1.508 & 1.507 \\
C17-C18 & $1.55(26)$ & $1.56(2)$ & & 1.509 & 1.509 \\
C16-C18 & $1.43(1)$ & $1.39(2)$ & & 1.510 & 1.510 \\
\hline
\end{tabular}




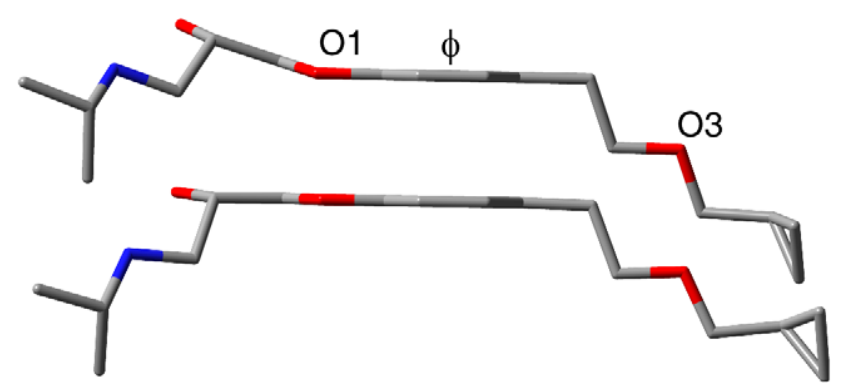

Fig. 6. Betaxolol molecule structure A before (top) and after optimization (bottom).

guide to interpret the molecular structure in the electronic point of view. In energetic terms, hyperconjugation is an important effect $[11,12]$ in which an occupied Lewis-type natural bond orbital is stabilized by overlapping with a non Lewis-type orbital (either one-center Rydberg or two-center antibonding NBO). This electron delocalization can be described as a charge transfer from a Lewis valence orbital (donor), with a decreasing of its occupancy, to a non-Lewis orbital (acceptor). Several other types of types of valuable data, such as directionality, hybridization and partial charges, were analyzed in the output of NBO analysis.

Since the polar atoms of the betaxolol molecular backbone are involved in intra and intermolecular hydrogen bonds, the NBOs centered on these atoms deserve particular attention. In view of its special chemical and biochemical behaviour, the structure of the cyclopropyl group will be also object of study.

First, let us consider the betaxolol single point molecular backbone from the isopropyl head till the $\mathrm{O} 3$ atom, which is a common fragment to both A and B molecules. Among the most important interactions between Lewis and non-Lewis orbitals, those in which $\mathrm{N}$ and $\mathrm{O}$ lone pairs act as donors stand out. In Table 4 are quoted the second-order perturbation energy values, $E_{i j *}^{(2)}$, corresponding to these interactions. Also included are the overlap integral of each orbital pair.

A very strong interaction is observed between the $\pi$ type orbital containing the lone electron pair of $\mathrm{O} 1$ and the neighbor $\mathrm{C}-\mathrm{C} \pi^{*}$ antibond orbital of the benzene ring. A contour diagram showing this interaction is presented in Fig. 7. The displacement of the contour lines of the $\pi$ electrons of $\mathrm{C} 7$ towards the $\mathrm{n}\left(\mathrm{LP}_{2} \mathrm{O} 1\right)$ orbital and the overlap of the donor and acceptor orbitals are notorious. This interaction is responsible for a pronounced decrease of the lone pair orbital occupancy. The hyperconjugation between 01 and the benzene ring defines the central plane of the betaxolol backbone, which is a common molecular feature of this type of drugs. An important contribution for the molecular stabilization is further given by 01 through the overlap of its $\mathrm{sp}^{1.54}$ lone pair $\mathrm{n}\left(\mathrm{LP}_{1} \mathrm{O} 1\right)$ with the $\sigma^{*}(\mathrm{C} 7-\mathrm{C} 12)$ orbital.

No interaction was observed for $\mathrm{n}\left(\mathrm{LP}_{2} \mathrm{O} 1\right) \rightarrow \sigma^{*}\left(\mathrm{C} 3-\mathrm{H}^{\prime}\right)$ above the threshold of $2 \mathrm{~kJ} \mathrm{~mol}^{-1}$. Thus, there is no evidence for the intramolecular $\mathrm{C} 3-\mathrm{H}^{\prime} \ldots \mathrm{O} 1$ hydrogen bond, according to the NBO

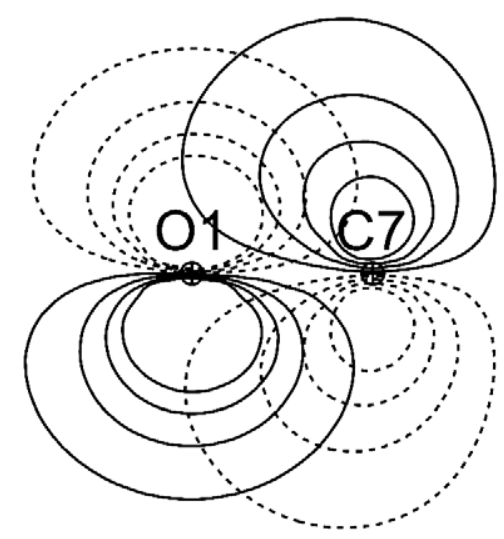

Fig. 7. Contour diagram corresponding $\mathrm{n}\left(\mathrm{LP}_{2} \mathrm{O} 1\right) \rightarrow \pi^{*}(\mathrm{C} 7-\mathrm{C} 12)$ in the plane perpendicular to $01-\mathrm{C} 7-\mathrm{C} 12$. The $\mathrm{C} 12$ nucleus is out of the plane.

method. An analysis of the electrostatic properties of the fragment did not provide evidence for any significant electrostatic interaction, either.

According to the tabulated values for the stabilizing energy caused by orbital overlapping, the electronic structure of atoms $\mathrm{O} 2$ and $\mathrm{N} 1$ play an important role in the backbone definition of the betaxolol.

As it is evidenced by X-ray diffraction, two conformations are present in the crystalline betaxolol. They differ from one another by the molecular backbone from $\mathrm{O} 3$ to the molecular end. The electronic structure around the $\mathrm{O} 3$ atom was examined by NBO analysis in order to interpret the two different structures. Characteristic data of $\mathrm{O} 3$ lone pair orbitals and the main interaction with unfilled orbitals are given in Table 5.

Regarding the interaction of $\mathrm{n}\left(\mathrm{LP}_{2} \mathrm{O} 3\right)$ orbital with bonds involving C15, Table 5 shows that structure $A$ is stabilized by two main orbital interactions, $\mathrm{n}\left(\mathrm{LP}_{2} \mathrm{O} 3\right) \rightarrow \sigma^{*}\left(\mathrm{C} 15-\mathrm{H}^{\prime \prime}\right)$ and $\mathrm{n}\left(\mathrm{LP}_{2} \mathrm{O} 3\right) \rightarrow$ $\sigma^{*}\left(\mathrm{C} 15-\mathrm{H}^{\prime}\right)$, corresponding to 22.78 and $11.05 \mathrm{~kJ} \mathrm{~mol}^{-1}$, respectively. The direction of the $\mathrm{n}\left(\mathrm{LP}_{2}\right)$ orbital specified in polar $(\theta)$ and azimuthal $(\varphi)$ coordinates is $\theta=48.2^{\circ}$ and $\varphi=260.5^{\circ}$. In structure $\mathrm{B}$, the $\mathrm{n}\left(\mathrm{LP}_{2}\right)$ orbital orientation of the $\mathrm{n}\left(\mathrm{LP}_{2}\right)$ is $\theta=67.0^{\circ}$ and $\varphi=269.4^{\circ}$ and there is an inversion of the wavefunction phase. In structure $\mathrm{B}$, the main stabilizing interactions are $\mathrm{n}\left(\mathrm{LP}_{2} \mathrm{O} 3\right) \rightarrow \sigma^{*}\left(\mathrm{C} 15-\mathrm{H}^{\prime}\right)$ and $\mathrm{n}\left(\mathrm{LP}_{2} \mathrm{O} 3\right) \rightarrow \sigma^{*}(\mathrm{C} 15-\mathrm{C} 16)$ with energies of 25.29 and $15.03 \mathrm{~kJ} \mathrm{~mol}^{-1}$, respectively. In Fig. 8 are represented the $3 \mathrm{D}$ views and $2 \mathrm{D}$ contour of the $\mathrm{n}\left(\mathrm{LP}_{2} \mathrm{O} 3\right)$ interaction with $\sigma^{*}\left(\mathrm{C} 15-\mathrm{H}^{\prime \prime}\right)$ in conformer A and with $\sigma^{*}\left(\mathrm{C} 15-\mathrm{H}^{\prime}\right)$ in conformer B. The overlap integral is $S=-0.1719$ for the first and $S=0.1780$ for the latter.

The structure of cyclopropane has been subject of curiosity and theoretical and experimental research for a very long time. The high strain energy of a planar three-carbon ring with eclipsed C$\mathrm{H}$ bonds on neighboring carbon atoms contrasted with the stability shown by the molecule is a rather intriguing question. Various

Table 4

Interaction between occupied and antibond NBOs in betaxolol

\begin{tabular}{|c|c|c|c|c|c|}
\hline Lone pair & Occupancy & Hybrid (\% p character) & Donor-acceptor interaction & $\mathrm{E}_{i j *}^{(2)} / \mathrm{kJ} \mathrm{mol}^{-1}$ & $S_{i j}^{*}$ \\
\hline $\mathrm{LP}_{2} \mathrm{O}_{1}$ & 1.86020 & $\mathrm{sp}^{99.99}(99.81)$ & $\begin{array}{l}\mathrm{n}\left(\mathrm{LP}_{2} \mathrm{O}_{1}\right) \rightarrow \pi^{*}(\mathrm{C} 7-\mathrm{C} 12) \\
\mathrm{n}\left(\mathrm{LP}_{2} \mathrm{O}_{1}\right) \rightarrow \sigma^{*}\left(\mathrm{C} 1-\mathrm{H} 1^{\prime}\right)\end{array}$ & $\begin{array}{r}117.15 \\
21.31\end{array}$ & $\begin{array}{r}-0.2567 \\
0.1646\end{array}$ \\
\hline $\mathrm{LP}_{1} \mathrm{O}_{1}$ & 1.96630 & $\mathrm{sp}^{1.54}(60.54)$ & $\mathrm{n}\left(\mathrm{LP}_{1} \mathrm{O}_{1}\right) \rightarrow \sigma^{*}(\mathrm{C} 7-\mathrm{C} 12)$ & 30.14 & -0.2201 \\
\hline $\mathrm{LP}_{2} \mathrm{O}_{2}$ & 1.95456 & $\mathrm{sp}^{99.99}(99.56)$ & $\begin{array}{l}\mathrm{n}\left(\mathrm{LP}_{2} \mathrm{O}_{2}\right) \rightarrow \sigma^{*}(\mathrm{C} 1-\mathrm{C} 2) \\
\mathrm{n}\left(\mathrm{LP}_{2} \mathrm{O}_{2}\right) \rightarrow \sigma^{*}(\mathrm{C} 2-\mathrm{C} 3)\end{array}$ & $\begin{array}{l}30.10 \\
13.82\end{array}$ & $\begin{array}{l}-0.1922 \\
-0.1186\end{array}$ \\
\hline $\mathrm{LP}_{1} \mathrm{O}_{2}$ & 1.98689 & $\mathrm{sp}^{1.20}(54.43)$ & $\mathrm{n}\left(\mathrm{LP}_{1} \mathrm{O}_{2}\right) \rightarrow \sigma^{*}(\mathrm{C} 2-\mathrm{H} 2)$ & 9.96 & 0.1353 \\
\hline $\mathrm{LPN}_{1}$ & 1.93408 & $\mathrm{sp}^{5.90}(85.43)$ & $\begin{array}{l}\mathrm{n}(\text { LPN1 }) \rightarrow \sigma^{*}(\mathrm{C} 4-\mathrm{C} 5) \\
\mathrm{n}(\mathrm{LPN} 1) \rightarrow \sigma^{*}\left(\mathrm{C} 3-\mathrm{H}^{\prime}\right)\end{array}$ & $\begin{array}{l}35.21 \\
21.77\end{array}$ & $\begin{array}{l}-0.2255 \\
-0.1705\end{array}$ \\
\hline
\end{tabular}


Table 5

Orbital interactions of $\mathrm{O3}$ lone pair

\begin{tabular}{|c|c|c|c|c|c|}
\hline Lone pair & Occupancy & Hybrid (\% p character) & Donor-acceptor interaction & $\mathrm{E}_{i j *}^{(2)} / \mathrm{kJ} \mathrm{mol}^{-1}$ & $S_{i j}^{*}$ \\
\hline \multicolumn{6}{|l|}{$A$} \\
\hline \multirow[t]{4}{*}{$\mathrm{LP}_{2} \mathrm{O} 3$} & 1.94550 & $\mathrm{sp}^{99.99}(99.89)$ & $\mathrm{n}(\mathrm{LP} 2 \mathrm{O} 3) \rightarrow \sigma^{*}\left(\mathrm{C} 14-\mathrm{H}^{\prime}\right)$ & 25.33 & 0.1692 \\
\hline & & & $\mathrm{n}(\mathrm{LP} 2 \mathrm{O} 3) \rightarrow \sigma^{*}\left(\mathrm{C} 14-\mathrm{H}^{\prime \prime}\right)$ & 18.71 & -0.1449 \\
\hline & & & $\mathrm{n}(\mathrm{LP} 2 \mathrm{O} 3) \rightarrow \sigma^{*}\left(\mathrm{C} 15-\mathrm{H}^{\prime \prime}\right)$ & 22.78 & -0.1719 \\
\hline & & & $\mathrm{n}(\mathrm{LP} 2 \mathrm{O} 3) \rightarrow \sigma^{*}\left(\mathrm{C} 15-\mathrm{H}^{\prime}\right)$ & 11.05 & 0.1109 \\
\hline \multirow[t]{2}{*}{$\mathrm{LP}_{1} \mathrm{O} 3$} & 1.97500 & $\mathrm{sp}^{1.09}(52.14)$ & $\mathrm{n}(\mathrm{LP} 103) \rightarrow \sigma^{*}\left(\mathrm{C} 15-\mathrm{H}^{\prime}\right)$ & 6.74 & -0.1225 \\
\hline & & & $\mathrm{n}(\mathrm{LP1O3}) \rightarrow \mathrm{Ry}^{*}(\mathrm{C} 14)$ & 6.66 & -0.3198 \\
\hline \multicolumn{6}{|l|}{$B$} \\
\hline \multirow[t]{4}{*}{$\mathrm{LP}_{2} \mathrm{O} 3$} & 1.93939 & $\mathrm{sp}^{99.99}(99.56)$ & $\mathrm{n}(\mathrm{LP} 2 \mathrm{O} 3) \rightarrow \sigma^{*}\left(\mathrm{C} 14-\mathrm{H}^{\prime \prime}\right)$ & 25.20 & 0.1673 \\
\hline & & & $\mathrm{n}(\mathrm{LP} 2 \mathrm{O} 3) \rightarrow \sigma^{*}\left(\mathrm{C} 14-\mathrm{H}^{\prime}\right)$ & 18.17 & -0.1428 \\
\hline & & & $\mathrm{n}(\mathrm{LP} 2 \mathrm{O} 3) \rightarrow \sigma^{*}\left(\mathrm{C} 15-\mathrm{H}^{\prime}\right)$ & 25.29 & 0.1780 \\
\hline & & & $\mathrm{n}(\mathrm{LP} 2 \mathrm{O} 3) \rightarrow \sigma^{*}(\mathrm{C} 15-\mathrm{C} 16)$ & 15.03 & 0.1214 \\
\hline $\mathrm{LP}_{1} \mathrm{O} 3$ & 1.97254 & $\mathrm{Sp}^{1.24}(55.34)$ & $\mathrm{n}(\mathrm{LP} 103) \rightarrow \sigma^{*}\left(\mathrm{C} 15-\mathrm{H}^{\prime \prime}\right)$ & 12.10 & 0.1464 \\
\hline
\end{tabular}

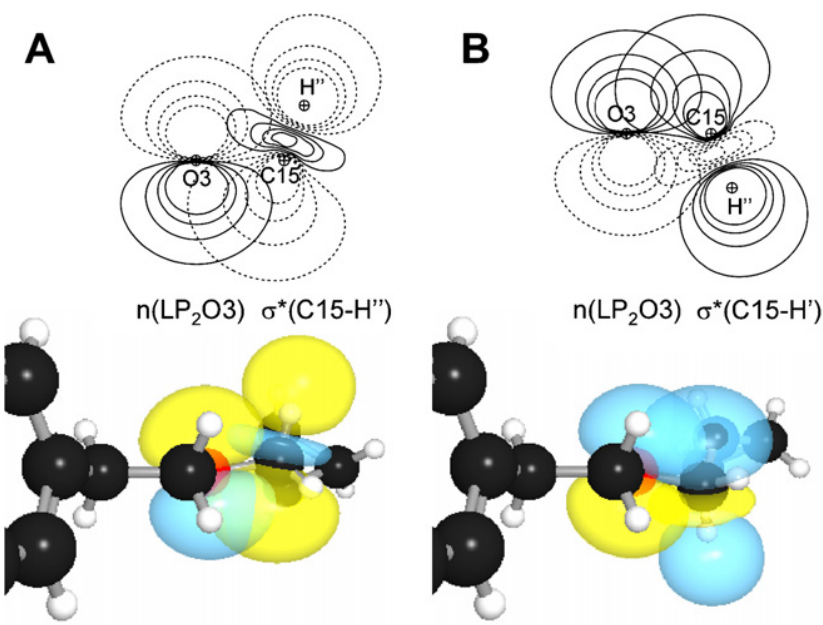

Fig. 8. Donor-acceptor interaction of $\mathrm{O} 3 \mathrm{p}$ type lone pairs and $\mathrm{C} 15-\mathrm{H}^{\prime \prime} \mathrm{NBO}$ antibond (A), C15- $\mathrm{H}^{\prime}$ NBO antibond (B). Top (2D contour), bottom (3D view).

structural models have been proposed for cyclopropane and its derivatives [13-19].
Owing to its high strain energy, cyclopropyl is a reactive group undergoing various types of reactions, making cyclopropyl derivatives useful compounds for a variety of purposes. The studies of enzymatic mechanism [20] detection of biochemical active sites [21], synthesis of conformational constrained aminoacids which are used in the preparation of peptides $[22,23]$ are examples of bioorganic reactions involving cyclopropyl groups. Therapeutic agents with cyclopropane as constituent are increasing [24-26]. Thus, the cyclopropyl is a betaxolol fragment deserving particular attention.

In Table 6 are depicted some data of NBO analysis of single point and optimized structures of the cyclopropyl group. For reference, data on the optimized cyclopropane molecule at the level of theory described above were also included. In A and B unoptimized crystal structures, the carbon natural hybrid orbitals (NHOs) are $\mathrm{sp}^{\lambda}$ with $\lambda$ varying between 2.8 (p character $75 \%$ ) and $5.44(\mathrm{p}$ $84 \%$ ). The values of $\lambda$ in the optimized structures are more uniform $(3.54<\lambda<3.73$, p character $78-79 \%)$ figures close to those observed in cyclopropane $(\lambda=3.60$, p $78 \%)$.

The NHOs are oriented $19.5-27.4^{\circ}$ away from the straight line connecting the carbon nuclei (Fig. 9a). Single point structures A and $\mathrm{B}$ exhibit identical patterns and the NHOs of both show a deviation of about $23^{\circ}$ after optimizing, which is close to the value found for cyclohexane. The NBOs resulting from the NHOs are bent

Table 6

Bond and antibond C-C stabilizing interactions in the cyclopropyl group

\begin{tabular}{|c|c|c|c|c|c|c|c|}
\hline \multirow[t]{2}{*}{ Bond } & \multirow[t]{2}{*}{ Occupancy } & \multirow[t]{2}{*}{ NBO composition } & \multicolumn{2}{|c|}{ Deviation from line of nuclear centers $\left(^{\circ}\right)$} & \multirow[t]{2}{*}{ Donor-acceptor interaction } & \multirow[t]{2}{*}{$\mathrm{E}_{i j *}^{(2)} / \mathrm{kJ} \mathrm{mol}^{-1}$} & \multirow[t]{2}{*}{$S_{i j}^{*}$} \\
\hline & & & 1 st NHO & 2nd NHO & & & \\
\hline \multicolumn{8}{|c|}{ A single point structure } \\
\hline $\mathrm{C} 16-\mathrm{C} 17$ & 1.95021 & $0.7051\left(\mathrm{sp}^{5.44}\right)_{\mathrm{c} 16}+0.7091\left(\mathrm{sp}^{4.03}\right)_{\mathrm{c} 17}$ & 22.3 & 22.9 & $\begin{array}{l}\sigma(\mathrm{C} 16-\mathrm{C} 17) \rightarrow \sigma^{*}(\mathrm{C} 16-\mathrm{C} 18) \\
\sigma(\mathrm{C} 16-\mathrm{C} 17) \rightarrow \sigma^{*}(\mathrm{C} 17-\mathrm{C} 18)\end{array}$ & $\begin{array}{l}21.69 \\
32.49\end{array}$ & $\begin{array}{r}-0.2807 \\
0.2951\end{array}$ \\
\hline $\mathrm{C} 17-\mathrm{C} 18$ & 1.96178 & $0.7069\left(\mathrm{sp}^{4.67}\right)_{\mathrm{c} 17}+0.7073\left(\mathrm{sp}^{4.74}\right)_{\mathrm{c} 18}$ & 24.7 & 24.4 & $\begin{array}{l}\sigma(\mathrm{C} 17-\mathrm{C} 18) \rightarrow \sigma^{*}(\mathrm{C} 16-\mathrm{C} 17) \\
\sigma(\mathrm{C} 17-\mathrm{C} 18) \rightarrow \sigma^{*}(\mathrm{C} 16-\mathrm{C} 18)\end{array}$ & $\begin{array}{l}33.49 \\
27.72\end{array}$ & $\begin{array}{l}-0.2897 \\
-0.2843\end{array}$ \\
\hline $\mathrm{C} 16-\mathrm{C} 18$ & 1.96086 & $0.7078\left(\mathrm{sp}^{2.97}\right)_{\mathrm{c} 16}+0.7064\left(\mathrm{sp}^{3.19}\right)_{\mathrm{c} 18}$ & 20.8 & 19.5 & $\begin{array}{l}\sigma(\mathrm{C} 16-\mathrm{C} 18) \rightarrow \sigma^{*}(\mathrm{C} 16-\mathrm{C} 17) \\
\sigma(\mathrm{C} 16-\mathrm{C} 18) \rightarrow \sigma^{*}(\mathrm{C} 17-\mathrm{C} 18)\end{array}$ & $\begin{array}{l}19.59 \\
18.92\end{array}$ & $\begin{array}{l}0.3005 \\
0.2906\end{array}$ \\
\hline \multicolumn{8}{|c|}{ B single point structure } \\
\hline $\mathrm{C} 16-\mathrm{C} 17$ & 1.95628 & $0.7043\left(\mathrm{sp}^{3.84}\right)_{\mathrm{c} 16}+0.7099\left(\mathrm{sp}^{3.22}\right)_{\mathrm{c} 17}$ & 20.3 & 20.9 & $\begin{array}{l}\sigma(\mathrm{C} 16-\mathrm{C} 17) \rightarrow \sigma^{*}(\mathrm{C} 16-\mathrm{C} 18) \\
\sigma(\mathrm{C} 16-\mathrm{C} 17) \rightarrow \sigma^{*}(\mathrm{C} 17-\mathrm{C} 18)\end{array}$ & $\begin{array}{l}23.49 \\
31.48\end{array}$ & $\begin{array}{r}-0.3020 \\
0.3094\end{array}$ \\
\hline $\mathrm{C} 17-\mathrm{C} 18$ & 1.95220 & $0.7067\left(\mathrm{sp}^{5.38}\right)_{\mathrm{c} 17}+0.7075\left(\mathrm{sp}^{5.32}\right)_{\mathrm{c} 18}$ & 27.4 & 27.1 & $\begin{array}{l}\sigma(\mathrm{C} 17-\mathrm{C} 18) \rightarrow \sigma^{*}(\mathrm{C} 16-\mathrm{C} 17) \\
\sigma(\mathrm{C} 17-\mathrm{C} 18) \rightarrow \sigma^{*}(\mathrm{C} 16-\mathrm{C} 18)\end{array}$ & $\begin{array}{l}42.29 \\
39.02\end{array}$ & $\begin{array}{l}-0.2962 \\
-0.2899\end{array}$ \\
\hline C16-C18 & 1.96275 & $0.7048\left(\mathrm{sp}^{2.77}\right)_{\mathrm{c} 16}+0.7094\left(\mathrm{sp}^{2.93}\right)_{\mathrm{c} 18}$ & 21.7 & 19.9 & $\begin{array}{l}\sigma(\mathrm{C} 16-\mathrm{C} 18) \rightarrow \sigma^{*}(\mathrm{C} 16-\mathrm{C} 17) \\
\sigma(\mathrm{C} 16-\mathrm{C} 18) \rightarrow \sigma^{*}(\mathrm{C} 17-\mathrm{C} 18)\end{array}$ & $\begin{array}{l}22.90 \\
24.12\end{array}$ & $\begin{array}{l}-0.3134 \\
-0.3006\end{array}$ \\
\hline \multicolumn{8}{|c|}{$A$ and $B$ optimized structure } \\
\hline $\mathrm{C} 16-\mathrm{C} 17$ & 1.95587 & $0.7104\left(\mathrm{sp}^{3.66}\right)_{\mathrm{c} 16}+0.7038\left(\mathrm{sp}^{3.54}\right)_{\mathrm{c} 17}$ & 23.6 & 23.0 & $\begin{array}{l}\sigma(\mathrm{C} 16-\mathrm{C} 17) \rightarrow \sigma^{*}(\mathrm{C} 16-\mathrm{C} 18) \\
\sigma(\mathrm{C} 16-\mathrm{C} 17) \rightarrow \sigma^{*}(\mathrm{C} 17-\mathrm{C} 18)\end{array}$ & $\begin{array}{l}21.23 \\
23.07\end{array}$ & $\begin{array}{l}-0.3074 \\
-0.3023\end{array}$ \\
\hline C17-C18 & 1.96555 & $0.7051\left(\mathrm{sp}^{3.68}\right)_{\mathrm{c} 17}+0.7091\left(\mathrm{sp}^{3.65}\right)_{\mathrm{c} 18}$ & 23.9 & 23.8 & $\begin{array}{l}\sigma(\mathrm{C} 17-\mathrm{C} 18) \rightarrow \sigma^{*}(\mathrm{C} 16-\mathrm{C} 17) \\
\sigma(\mathrm{C} 17-\mathrm{C} 18) \rightarrow \sigma^{*}(\mathrm{C} 16-\mathrm{C} 18)\end{array}$ & $\begin{array}{l}24.33 \\
25.41\end{array}$ & $\begin{array}{r}-0.3006 \\
0.3030\end{array}$ \\
\hline C16-C18 & 1.95282 & $0.7103\left(\mathrm{sp}^{3.73}\right)_{\mathrm{c} 16}+0.7039\left(\mathrm{sp}^{3.54}\right)_{\mathrm{c} 18}$ & 23.4 & 23.2 & $\begin{array}{l}\sigma(\mathrm{C} 16-\mathrm{C} 18) \rightarrow \sigma^{*}(\mathrm{C} 16-\mathrm{C} 17) \\
\sigma(\mathrm{C} 16-\mathrm{C} 18) \rightarrow \sigma^{*}(\mathrm{C} 17-\mathrm{C} 18)\end{array}$ & $\begin{array}{l}21.60 \\
23.53\end{array}$ & $\begin{array}{l}-0.3085 \\
-0.3027\end{array}$ \\
\hline \multicolumn{8}{|c|}{ Cyclopropane } \\
\hline $\mathrm{C}-\mathrm{C}$ & 1.96800 & $0.7071\left(\mathrm{sp}^{3.60}\right)+0.7071\left(\mathrm{sp}^{3.60}\right)$ & 23.3 & 23.3 & $\sigma(C-C) \rightarrow \sigma^{*}(C-C)$ & 23.40 & 0.2029 \\
\hline
\end{tabular}



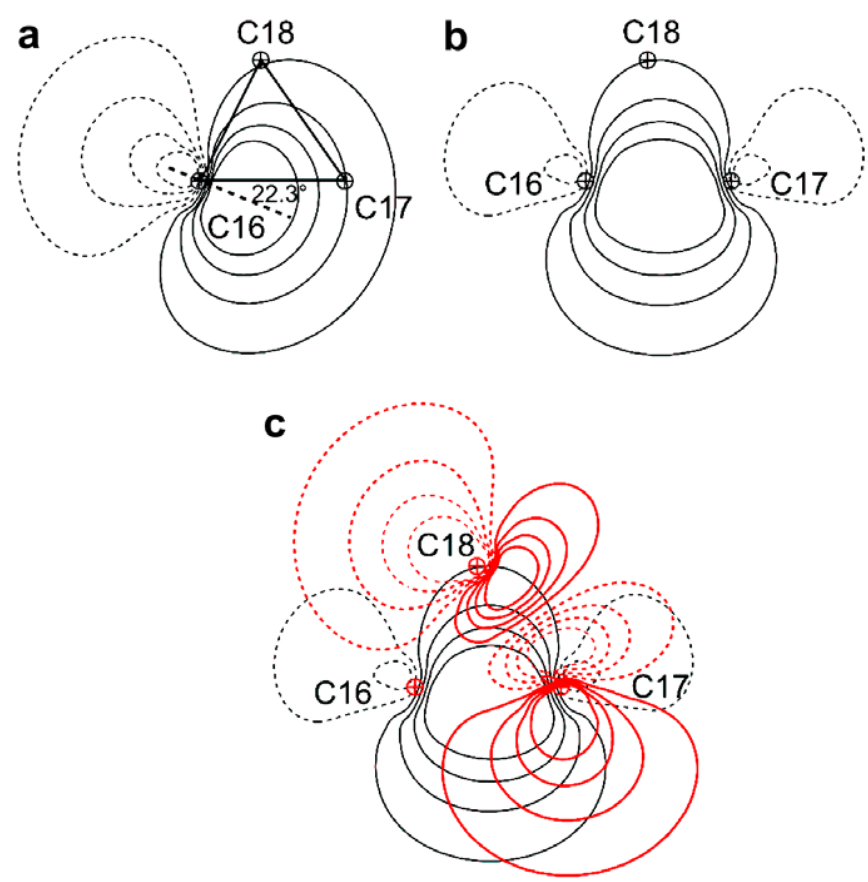

Fig. 9. Cyclopropyl contour diagram of (a) one of the NHOs that make up the C-C bond, detailing the deviation from the line of nuclear centers; (b) one of the bonding C-C bent orbital; (c) overlap between a bonding C-C NBO and a geminal antibonding $\mathrm{C}-\mathrm{C}$ NBO.
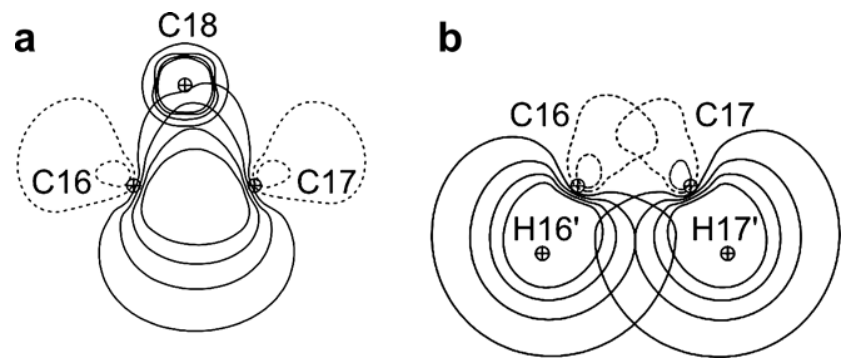

Fig. 10. Destabilizing overlaps of filled orbitals in the cyclopropyl group: (a) bonding $\sigma_{\mathrm{C}-\mathrm{C}} \leftrightarrow 1 \mathrm{~s}$ core of opposite carbon orbital; (b) bonding $\sigma_{\mathrm{C}-\mathrm{H}}$ orbitals between adjacent $\mathrm{C}-\mathrm{H}$.

orbitals as shown in Fig. 9b. The most important stabilizing orbital interactions are those occurring between $\mathrm{C}-\mathrm{C}$ filled orbitals and geminal C-C antibonds (Fig. 9c). In Table 6 are given the values of the second-order perturbation energy for these interaction and the corresponding overlap integrals. The stabilized NBO energies are as high as $153.9 \mathrm{~kJ} \mathrm{~mol}^{-1}$ in A and $183.30 \mathrm{~kJ} \mathrm{~mol}^{-1}$ in B. A diversity of values from 4.52 to $8.00 \mathrm{~kJ} \mathrm{~mol}^{-1}$ in $\mathrm{A}$ and from 5.47 to $10.10 \mathrm{~kJ} \mathrm{~mol}^{-1}$ in $\mathrm{B}$ is observed.

The differences between the $\mathrm{C}-\mathrm{C}$ bonds regarding NBO composition and orbital interactions vanish after the structural optimization. The cyclopropyl structure relaxes to that of cyclopropane. However, evidence for the substituent effect at C16 is visible in the small differences between the stabilizing orbital overlap energies. The deformation of the cyclopropyl group relatively to cyclopropane is mainly caused by the close packing and/or crystal field effects.

Steric repulsion between occupied orbitals is an important destabilizing effect. In the cyclopropyl group, the main orbital destabilizing interaction is between the $\mathrm{C}-\mathrm{C}$ bond orbitals and the core orbital of the opposite atoms (Fig. 10a). The energies of these interactions are within the range of $20-29 \mathrm{~kJ} \mathrm{~mol}^{-1}$. Further steric orbital repulsion occurs between neighboring $\mathrm{C}-\mathrm{H}$ with energy $8-12 \mathrm{~kJ} \mathrm{~mol}^{-1}$ and strong orbital overlaps (Fig. 10b).

\section{Conclusion}

The crystalline structure of betaxolol obtained from water:ethanol solution by evaporating at $25^{\circ} \mathrm{C}$ was resolved by single crystal $\mathrm{X}$-ray diffraction. The crystal is a mixture of $59 \%$ of conformation $\mathrm{A}$ and $41 \%$ of conformation $B$. The conformations differ only in the cyclopropylmethoxy moiety.

Natural Bond Orbital analysis shows that the particular spatial orientation of this cyclopropylmethoxy fragment arises from stabilizing interactions. In conformer $\mathrm{A}$, this is primarily caused by the overlap of the $\mathrm{O} 3$ lone pair with the greater p-character, $\mathrm{n}\left(\mathrm{LP}_{2} \mathrm{O} 3\right)$, with the $\mathrm{C} 15-\mathrm{H}^{\prime \prime}$ and $\mathrm{C} 15-\mathrm{H}^{\prime}$ antibonding orbitals. In conformer $\mathrm{B}$, the same $\mathrm{n}\left(\mathrm{LP}_{2} \mathrm{O} 3\right)$ orbital interacts mostly with the $\mathrm{C} 15-\mathrm{H}^{\prime}$ and C15-C16 antibonding orbitals. The conformations of the cyclopropylmethoxy are such that the cyclopropyl groups of both conformations lie in perpendicular planes.

The bent bond orbitals typical of cyclopropyl were observed and the orbital interactions accountable for its remarkable stability were analyzed. Optimizing the structure given by X-ray at the B3LYP/6-31(d,p) level, the structure of both betaxolol conformations is slightly distended and the differences between bond lengths and angles in the cyclopropyl groups are dissipated with the values of geometrical parameters of both groups tending to those of cyclopropane.

\section{References}

[1] R.A. Esteves de Castro, J. Canotilho, R.M. Barbosa, M.R. Silva, A.M. Beja, J.A. Paixao, S. Redinha, Cryst. Growth Des. 7 (2007) 496.

[2] B.B. Hoffman, in: J.G. Hardman, L.E. Limbird, A.G. Gilman (Eds.), The Pharmacological Basis of Therapeutics, McGraw-Hill, New York, 2001, p. 215.

[3] A.L. Speck, HELENA. CAD-4 Data Reduction Program, University of Utrecht, The Netherlands, Utrecht, 1997.

[4] G.M. Sheldrick, SHELX97 \& SHELXL97, Institüt für Anorganische Chemie der Unicersität, Gottingen, Germany, 1997.

[5] C.K. Johnson, ORTEPII, Report ORNL-5138, Oak Ridge National Laboratory, Tennessee, USA, 1976.

[6] F.H. Allen, Acta Crystallogr. Sect. B 36 (1980) 81

[7] A.D. Becke, J. Chem. Phys. 98 (1993) 5648.

[8] P.J. Stephens, J. Phys. Chem. 98 (1994) 11623.

[9] M.W. Schmidt, K.K. Baldridge, J.A. Boatz, S.T. Elbert, M.S. Gordon, J.H. Jensen, S. Koseki, N. Matsunaga, K.A. Nguyen, S.J. Su, T.L. Windus, M. Dupuis, J.A. Montgomery, J. Comput. Chem. 14 (1993) 1347.

[10] E.D. Glendening, J.K. Badenhoop, A.E. Reed, J.E. Carpenter, J.A. Bohmann, C.M. Morales, F. Weinhold, NBO 5.0, Theoretical Chemistry Institute, University of Wisconsin, Madison, 2001.

[11] F. Weinhold, Nature 411 (2001) 539.

[12] F. Weinhold, C. Landis, Valency and Bonding: A Natural Bond Orbital DonorAcceptor Perspective, Cambridge University Press, Cambridge, 2005.

[13] J.F. Liebman, A. Greenberg, Chem. Rev. 76 (1976) 311.

[14] K.B. Wiberg, Angew. Chem. Int. Ed. 25 (1986) 312.

[15] D. Cremer, J. Gauss, J. Am. Chem. Soc. 108 (1986) 7467.

[16] J.B. Conant, in: Z. Rappoport (Ed.), The Chemistry of the Cyclopropyl Group, J. Wiley \& Sons, Chichester, 1995, p. 1.

[17] D. Cremer, in: Z. Rappoport (Ed.), The Chemistry of the Cyclopropyl Group, J Wiley \& Sons, Chichester, 1995, p. 43.

[18] T. Iijima, T. Kondou, T. Takenaka, J. Mol. Struct. 445 (1998) 23.

[19] M. Traetteberg, P. Bakken, J.V. Quesada, V.S. Mastryukov, J.E. Boggs, J. Mol. Struct. 485-486 (1999) 73.

[20] C.J. Suckling, Angew. Chem. Int. Ed. 27 (1988) 537.

[21] P.B.M.W.M. Timmermans, Medicinal Chemistry, in: R. Dahlbom, J.G.L. Nillsson (Eds.), Swedish Pharmaceutical Press, Stockholm, 1985, p. 69.

[22] L. Colombo, Tetrahedron Lett. 36 (1995) 625.

[23] A.D. Headley, Bioorg. Chem. 31 (2003) 99.

[24] C. Cativiela, Tetrahedron 53 (1997) 4479.

[25] C. Craig, K. Christine, WO 98/17274, 1998

[26] A.P. Ayala, H.W. Siesler, S.M.S.V. Wardell, N. Boechat, V. Dabbene, S.L. Cuffini, J. Mol. Struct. 828 (2007) 201. 